\title{
Factors Associated with Hepatitis A Vaccination Receipt in One-Year-Olds in the State of Michigan
}

\author{
Andrea L. Weston ${ }^{1,2}$ and Kyle S. Enger ${ }^{1}$ \\ ${ }^{1}$ Division of Immunization, Michigan Department of Community Health, Lansing, MI 48909, USA \\ ${ }^{2}$ Department of Epidemiology, University of Michigan, Ann Arbor, MI 48109-2029, USA
}

Correspondence should be addressed to Andrea L. Weston, weston.andrea@gmail.com

Received 25 June 2009; Accepted 16 September 2009

Academic Editor: Robert T. Chen

Copyright (C) 2010 A. L. Weston and K. S. Enger. This is an open access article distributed under the Creative Commons Attribution License, which permits unrestricted use, distribution, and reproduction in any medium, provided the original work is properly cited.

\begin{abstract}
The objectives of this study were to determine factors associated with hepatitis A vaccination and to assess overall hepatitis A vaccination coverage levels among one-year-olds in Michigan. The study population was the first hepatitis A vaccination-eligible birth cohort $(n=134226)$ enrolled in the Michigan Care Improvement Registry (MCIR) after 2006 recommendations were made to routinely vaccinate all one-year-olds. All children whose first birthday occurred on or between May 1, 2006 and April 31, 2007 were included in the study population. Racial/ethnic minorities had increased odds of receiving the hepatitis A vaccination in Michigan, and Medicaid and WIC status modified this relationship. Fully understanding these relationships will be useful in targeting vaccination outreach and education programs.
\end{abstract}

\section{Introduction}

Hepatitis A was one of the most frequently reported vaccinepreventable diseases in the United States in the 1990s [1]. Typically, infection rates in the U.S. were higher in children under six years of age, adults over 50 years of age, American Indians, Alaska Natives, Hispanics, and lower socioeconomic groups [1-7]. Since hepatitis A vaccination introduction, infection rates in the U.S. have dropped drastically, especially in groups with the highest disease incidence historically $[3-5,8]$.

The Advisory Committee for Immunization Practices (ACIP) made initial recommendations in 1996 to vaccinate all high-risk groups (i.e., travelers and IV drug users), and the target populations have been expanded several times [9-11]. The 1999 recommendations included routine vaccination of children $\geq 2$ years of age living in areas with hepatitis $\mathrm{A}$ incidence consistently $\geq 2$ times the national average of 10 cases per 100000 ; this included 11 states located in western and southwestern regions of the United States [10]. In May, 2006, the ACIP recommended routine vaccination of all 12 23 month old children in the United States with 2 doses at least 6 months apart [11].
In 2003, data collected from the National Immunization Survey (NIS) showed $50.9 \%$ coverage ( $\geq 1$ dose) among 24 to 35 month old children in the 11 states where recommendations for routine vaccination had been made versus only $1.4 \%$ of children in the same age group in the rest of the country [2]. Some studies have found significant postrecommendation increases in vaccination receipt and decreases in hepatitis A incidence among American Indians and Alaska Natives [2,5]. Other groups that have had significantly increased odds of receiving the hepatitis A vaccination include women, people with public (as opposed to private) health providers, children living in urban areas, and children born to mothers with lower levels of education $[2,7,12,13]$.

Michigan Care Improvement Registry (MCIR), Michigan's Immunization Information System (IIS) has collected data on hepatitis A vaccination in one-year-olds since the recommendation has been implemented in Michigan. MCIR is one of the leading IISs in participating number of children younger than 6 years, and in participating public and private vaccination provider sites $[14,15]$.

The primary goal of this study was to determine factors associated with hepatitis A vaccination in one-year-olds in 
Michigan after the 2006 routine recommendations were implemented. It was hypothesized that being Hispanic, being American Indian, being of lower socioeconomic status (by Medicaid and WIC status), and living in nonrural areas would all increase the odds of vaccination receipt in Michigan, similar to findings in other states. A secondary objective was to assess overall hepatitis A vaccination coverage levels among one-year-olds in Michigan.

\section{Materials and Methods}

2.1. Study Population. The study population contained 134226 one-year-olds in MCIR who had their first birthday on or between May 1, 2006 and April 31, 2007. These children were the first eligible cohort of one-year-olds for hepatitis A vaccination following ACIP's May 2006 recommendations for universal vaccination.

2.2. Data Source. This study uses data from the Michigan Care Improvement Registry (MCIR). At the end of 2007, more than $95 \%$ of children $19-35$ months of age had at least two recorded vaccinations in MCIR, and approximately $91 \%$ of the 2255 Michigan childhood vaccination providers submitted data to MCIR from July to December 2007 [16]. Coverage estimates from the MCIR generally fall within the 95\% confidence limits of Michigan's vaccination coverage measures in 19-35 month olds according to the National Immunization Survey (K. Enger, unpublished observations).

2.3. Outcome and Predictor Variables. The primary outcome variable was receipt of at least one dose of hepatitis A vaccination by the time the child turned two. The explanatory variables tested were gender, race/ethnicity, mother's age, number of months the vaccination recommendation was in effect by the child's first birthday, provider type (public versus private), Medicaid status, WIC status, rurality, and geographic region within the state, defined by MCIR region (Figure 1). Medicaid and WIC status were defined as anyone enrolled in Medicaid and/or WIC at the time the child turned one (when they were first eligible for vaccination receipt). The rurality variable was created using Categorization $\mathrm{F}$ of the University of Washington's Rural-Urban Commuting Area Codes (RUCAs) [17]. This classification system uses zip code and census tract commuting information to create categorizations of urban and rural areas. Categorization $\mathrm{F}$ created a rural category where only those areas that have little to no commuting of residents to larger areas for recreation or work are classified as rural. This can be thought of as "nonurban and nonlarge rural" [17].

2.4. Analysis. Descriptive statistics were used to describe the study population and assess vaccination coverage following the recommendations. Differences in child characteristics by vaccination status were assessed using chi-square tests for categorical variables and ANOVAs for continuous variables. Unadjusted logistic regression models were also used as a means of calculating odds ratios and $95 \%$ confidence intervals to assess the relationships between covariates and hepatitis A vaccination receipt. A main effects multivariable logistic regression model was used to determine adjusted measures of association, adjusted for all covariates with $P<$ .05 at the bivariate level. All possible two-way interactions of race/ethnicity with Medicaid/WIC status and two-way interactions between race/ethnicity and provider type were assessed in other logistic regression models. The main effects model was compared with the full model (containing the interaction terms) using the likelihood ratio test to determine if an interaction effect was present.

All statistical analyses were conducted using SAS version 9.1. This study was approved by the institutional review boards of the Michigan Department of Community Health and the University of Michigan.

\section{Results}

There were 134226 one-year-olds included in these analyses; $15540(11.6 \%)$ were excluded from multivariable analyses due to missing values for $\geq 1$ variables. Of all MCIR-enrolled one-year-olds, $55.8 \%(n=74885)$ received at least one dose of the vaccine by the time of their second birthday. Specific coverage rates varied by race/ethnicity, Medicaid and WIC status, mother's age, time the recommendation had been in effect by the child's first birthday, and geographic location (Table 1). By the time of a child's second birthday, only $0.06 \%$ $(n=81)$ received a full two-dose series.

The multivariable logistic regression model with interaction terms for race/ethnicity and Medicaid/WIC status was significantly different from the main effects model, based on the log-likelihood test with $P<.05$, and will therefore be the only multivariable model reported. In the multivariable model (Table 2), the odds of vaccination differed significantly by race/ethnicity, provider type, Medicaid/WIC enrollment, residence in a rural ZIP code, and by region within Michigan. Compared to one-year-olds who were white, each of the minority race/ethnic groups had statistically higher odds of receiving a vaccination: Asian and Asian Pacific Islander (Odds ratio $[\mathrm{OR}]=1.75 ; 95 \%$ Confidence Interval $[\mathrm{CI}]: 1.58,1.95)$, black $(\mathrm{OR}=1.09 ; 95 \%$ CI: 1.01, 1.29), and Hispanic (OR $=1.16 ; 95 \%$ CI: 1.07, 1.26) (Table 2). Children visiting a public provider were more likely to receive the vaccination than children seeing a private provider $(\mathrm{OR}=1.19 ; 95 \% \mathrm{CI}: 1.13,1.25)$ (Table 2). Children on Medicaid and WIC together had increased odds $(\mathrm{OR}=1.38 ; 95 \% \mathrm{CI}: 1.31,1.44)$ of vaccination receipt when compared to children receiving neither service (Table 2). Children living in rural areas had decreased odds $(\mathrm{OR}=0.88 ; 95 \%$ CI: $0.80,0.96)$ of receiving a vaccination, when compared to children living in nonrural areas (Table 2). Northern, less-populated areas of Michigan (regions 3,5, and 6) were less likely to be vaccinated than southern, more densely populated areas (regions 1,2 , and 4 ) (Table 2 and Figure 1).

Significant interaction was also present between Hispanic or black race/ethnicity and Medicaid/WIC enrollment (Table 2). Among children with Medicaid, Hispanic children had $1.83(95 \%$ CI: $1.40,2.41)$ times the odds of being 


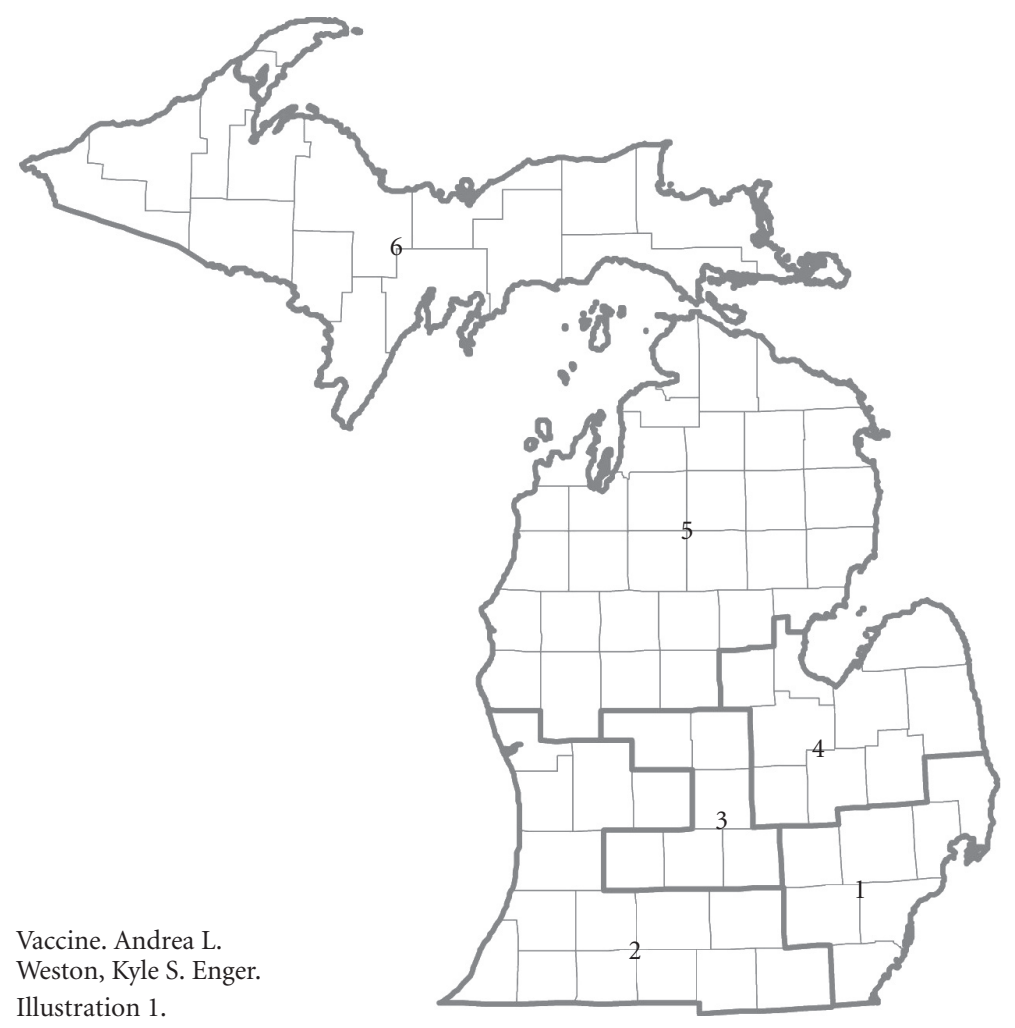

FIgure 1: Regional map of the State of Michigan, as defined by Michigan Care Improvement Registry (MCIR).

vaccinated than white children. Among children with WIC, Hispanic children $(\mathrm{OR}=1.35 ; 95 \%$ CI: 1.10, 1.67$)$ and black children $(\mathrm{OR}=1.17 ; 95 \%$ CI: $1.01,1.34)$ had increased odds of vaccination receipt when compared to white children (Table 2). Compared to white children on both Medicaid and WIC, black children $(\mathrm{OR}=1.17 ; 95 \% \mathrm{CI}: 1.05,1.29)$ and Hispanic children (OR $=1.32$; 95\% CI: 1.12, 1.56) again had increased odds of receiving the vaccination (Table 2).

\section{Discussion}

Hepatitis A vaccination was statistically associated with race/ethnicity, provider type, region, mother's age, time the recommendation had been in effect by the child's first birthday, and rurality in Michigan. Hispanic and black children receiving Medicaid, WIC, or both have increased odds of receiving the vaccination. These results are in contrast to the general trend of lower vaccination coverage among minority groups [18] and indicate that something may be differentiating promotion and administration of the hepatitis A vaccine from other vaccines. These results suggest that WIC and Medicaid may be promoting hepatitis A vaccination more effectively for Hispanic and black children than for white children.

Our results are consistent with the previous findings showing that Hispanic children, children with public insurance (and probably lower socioeconomic status), and children who live in nonrural areas have increased odds of hepatitis A vaccination receipt $[2,7,12,13]$. One possible explanation for this could be that some groups of children are being targeted more because they have historically had a high risk for the disease [1]. Another possible explanation for our results could be physicians having different knowledge about the vaccine and/or the recommendation [19].

The high coverage rate $(55.79 \%)$ with 1 or more doses of hepatitis A vaccination in the first cohort of one-year-olds eligible for routine vaccination is remarkable. For example, the CDC recommended that all 6 to 23 month year olds in the U.S. should be vaccinated for influenza for the 2002-2003 season, but only $7.4 \%$ of that age group received at least 1 influenza vaccination [20]. Furthermore, in the 2006-2007 influenza season, only $31.8 \%$ of that age group had received at least 1 influenza vaccination [20, 21]. In Michigan, hepatitis A coverage has also risen much more rapidly than varicella vaccination. Although varicella and hepatitis A vaccinations are both recommended at the first birthday, it took three years following varicella recommendations for coverage to reach $39.6 \%$ [22]. While less than $1 \%$ of these children received a full two-dose series by the time of their second birthday, we believe this is probably explained in large part by the recommendation stating vaccinations to be at least 6 months apart, so many children probably go longer than the 6 month minimum before receiving the second dose. It is important to note, however, that the 6month interval between first and second doses is longer than other recommended vaccination intervals, which may lead to failure of followup of the second dose. Many children may 
TABLE 1: Baseline characteristics, by hepatitis A vaccination receipt ${ }^{\mathrm{a}}$ coverage.

\begin{tabular}{|c|c|c|c|c|}
\hline Characteristic & $\begin{array}{l}\text { Percentage with } \\
\text { characteristic } \\
(n=134226)\end{array}$ & $\begin{array}{l}\text { Coverage (\%) with } \geq 1 \\
\text { dose of the vaccination }\end{array}$ & $P$-value* & $\begin{array}{l}\text { Unadjusted odds ratio } \\
(95 \% \mathrm{CI})^{\mathrm{d}}\end{array}$ \\
\hline Entire population & 100.0 & $55.8 \%$ & NA & \\
\hline \multicolumn{5}{|l|}{ Categorical variables } \\
\hline Gender, female & $48.8 \%$ & $56.1 \%$ & .08 & $1.02(1.00,1.04)$ \\
\hline \multicolumn{5}{|l|}{ Race/Ethnicity } \\
\hline American Indian & $0.6 \%$ & $58.8 \%$ & .14 & $1.12(0.96,1.29)$ \\
\hline Asian/Pacific Islander & $3.2 \%$ & $62.6 \%$ & $<.001$ & $1.32(1.24,1.40)$ \\
\hline Black (non-Hispanic) & $16.6 \%$ & $62.5 \%$ & $<.001$ & $1.37(1.33,1.41)$ \\
\hline Hispanic & $6.2 \%$ & $65.3 \%$ & $<.001$ & $1.51(1.44,1.58)$ \\
\hline White (non-Hispanic) & $67.2 \%$ & $53.4 \%$ & $<.001$ & $0.67(0.65,0.69)$ \\
\hline \multicolumn{5}{|l|}{ Mother's Age } \\
\hline$<20$ years & $9.0 \%$ & $57.5 \%$ & $<.001$ & $1.08(1.05,1.12)$ \\
\hline $20-34$ years & $72.5 \%$ & $55.9 \%$ & $<.001$ & $1.02(1.00,1.04)$ \\
\hline$>35$ years & $12.6 \%$ & $53.0 \%$ & $<.001$ & $0.88(0.85,0.91)$ \\
\hline \multicolumn{5}{|l|}{ Provider type, Public } \\
\hline Public & $6.4 \%$ & $60.7 \%$ & $<.001$ & $1.17(1.12,1.22)$ \\
\hline Private & $41.4 \%$ & $56.9 \%$ & $<.001$ & $0.86(0.82,0.90)$ \\
\hline \multicolumn{5}{|l|}{ Medicaid/WIC enrollment } \\
\hline Medicaid only ${ }^{\mathrm{b}}$ & $6.2 \%$ & $57.1 \%$ & .01 & $1.06(1.01,1.11)$ \\
\hline WIC only ${ }^{b}$ & $10.6 \%$ & $55.3 \%$ & .19 & $0.98(0.94,1.01)$ \\
\hline Both Medicaid and WIC ${ }^{b}$ & $30.3 \%$ & $64.1 \%$ & $<.001$ & $1.64(1.60,1.68)$ \\
\hline Neither Medicaid nor WIC ${ }^{\mathrm{b}}$ & $52.9 \%$ & $51.0 \%$ & $<.001$ & $0.66(0.65,0.67)$ \\
\hline Rural residence & $3.6 \%$ & $51.5 \%$ & $<.001$ & $0.79(0.74,0.83)$ \\
\hline \multicolumn{5}{|l|}{ MCIR Region } \\
\hline Region 1 & $45.9 \%$ & $58.5 \%$ & $<.001$ & $1.10(1.08,1.12)$ \\
\hline Region 2 & $24.4 \%$ & $58.7 \%$ & $<.001$ & $1.09(1.05,1.11)$ \\
\hline Region 3 & $5.8 \%$ & $51.5 \%$ & $<.001$ & $0.78(0.74,0.82)$ \\
\hline Region 4 & $10.1 \%$ & $59.6 \%$ & $<.001$ & $1.11(1.07,1.15)$ \\
\hline Region 5 & $6.9 \%$ & $49.5 \%$ & $<.001$ & $0.71(0.68,0.74)$ \\
\hline Region 6 & $2.4 \%$ & $47.3 \%$ & $<.001$ & $0.66(0.62,0.71)$ \\
\hline Continuous variable & $\begin{array}{l}\text { Mean for unvaccinated } \\
\text { population }(\mathrm{SD})\end{array}$ & $\begin{array}{l}\text { Mean for vaccinated } \\
\text { population }(\mathrm{SD})\end{array}$ & $P$-value & $\begin{array}{l}\text { Unadjusted odds ratio } \\
(95 \% \mathrm{CI})\end{array}$ \\
\hline $\begin{array}{l}\text { No. of months recommendation } \\
\text { in effect }\end{array}$ & $5.5(3.2)$ & $5.8(3.2)$ & $<.001$ & $1.03(1.02,1.03)$ \\
\hline
\end{tabular}

${ }^{a}$ Receipt of vaccination means the child has received one or more doses by the time of their 2 nd birthday.

${ }^{\mathrm{b}}$ Medicaid and WIC enrollment by the time of the child's first birthday.

${ }^{\mathrm{c}}$ No. months = number of months vaccination recommendation was in effect by child's 1st birthday.

${ }^{\mathrm{d}}$ Children with the given characteristic compared with children lacking the given characteristic.

${ }^{*} P$-values are from chi-square tests for categorical variables and ANOVA for continuous variables.

be visiting a doctor according to the American Academy of Pediatrics' well child visit schedule [23], and if a child visits a doctor just shortly before they are eligible to receive the second vaccination, they may go many months before seeing a doctor again, and the opportunity to vaccinate with the second dose may be missed.

The rapid uptake of hepatitis A vaccination may be due to the existence of the vaccine well before recommendations were implemented, improved vaccination promotion (including assessment of hepatitis A in MCIR), the degree of use prior to generalized recommendations for all children, perceived differences in severity between varicella and hepatitis disease or some combination of these. Another reason for the rapid uptake could be MCIR itself. As one article put it concisely, "IISs are among the most mature public health information systems that bridge the public health/clinical care divide" [15]. Within the last 20 years, vaccination schedules for children have gone from providing protection from seven infectious diseases, and a total of 11 doses in the 1980s, to providing protection from 16 
TABLE 2: Adjusted odds ratios and 95\% confidence intervals of hepatitis A vaccination receipt ${ }^{\mathrm{a}}$ among 1 -year-olds given by the final logistic regression model*.

\begin{tabular}{|c|c|c|}
\hline Variable & Odds Ratio & $95 \% \mathrm{CI}$ \\
\hline No. months ${ }^{\mathrm{b}}$ & 1.02 & $(1.02,1.03)$ \\
\hline \multicolumn{3}{|l|}{ Race/Ethnicity } \\
\hline White (non-Hispanic) & Reference & Reference \\
\hline American Indian & 1.24 & $(0.89,1.74)$ \\
\hline Asian/Pacific Islander & 1.75 & $(1.58,1.95)$ \\
\hline Black (non-Hispanic) & 1.09 & $(1.01,1.17)$ \\
\hline Hispanic & 1.14 & $(1.01,1.29)$ \\
\hline \multicolumn{3}{|l|}{ Mother's age } \\
\hline 20-34 years & Reference & Reference \\
\hline$<20$ years & 1.06 & $(1.00,1.13)$ \\
\hline$>35$ years & 0.98 & $(0.93,1.03)$ \\
\hline \multicolumn{3}{|l|}{ Provider Type } \\
\hline Private & Reference & Reference \\
\hline Public & 1.19 & $(1.13,1.25)$ \\
\hline \multicolumn{3}{|c|}{ Medicaid and WIC enrollment } \\
\hline Neither service & Reference & - \\
\hline Medicaid only ${ }^{c}$ & 1.14 & $(1.06,1.23)$ \\
\hline WIC onlyc & 0.98 & $(0.91,1.05)$ \\
\hline Both services $^{\mathrm{c}}$ & 1.38 & $(1.31,1.44)$ \\
\hline \multicolumn{3}{|l|}{ Geographic location } \\
\hline Rural residence & 0.88 & $(0.80,0.96)$ \\
\hline MCIR regions 1, 2 and 4 & Reference & Reference \\
\hline MCIR region 3 & 0.75 & $(0.70,0.81)$ \\
\hline MCIR region 5 & 0.75 & $(0.70,0.80)$ \\
\hline MCIR region 6 & 0.59 & $(0.53,0.66)$ \\
\hline Interaction Variables & OR & $95 \% \mathrm{CI}$ \\
\hline \multicolumn{3}{|l|}{ Medicaid enrollment $\mathrm{x}$} \\
\hline Hispanic & 1.83 & $(1.40,2.41)$ \\
\hline \multicolumn{3}{|l|}{ WIC enrollment $\mathrm{x}$} \\
\hline Black & 1.17 & $(1.01,1.34)$ \\
\hline Hispanic & 1.35 & $(1.10,1.67)$ \\
\hline \multicolumn{3}{|c|}{ Medicaid \& WIC enrollment $\mathrm{x}$} \\
\hline Black & 1.17 & $(1.05,1.29)$ \\
\hline Hispanic & 1.32 & $(1.12,1.56)$ \\
\hline
\end{tabular}

${ }^{a}$ Receipt of vaccination means the child has received one or more doses before their 2nd birthday.

${ }^{\mathrm{b}}$ No. months = number of months since the May 1, 2006 vaccination recommendation of the child's 1st birthday.

${ }^{\mathrm{c}}$ Medicaid and WIC enrollment on the child's first birthday.

* Logistic regression model run with a sample size of 118686 , due to missing/unknown values; all two-way interactions for race/ethnicity and Medicaid/WIC enrollment and race/ethnicity and provider type were tested for, but only those with significant $P$-values $(<.05)$ were included in the final model.

infectious diseases and a total of 30 to 40 doses in 2007 [24]. IISs allow all providers to have access to the most up to date vaccination information for every child to whom they are providing care, which helps keep track of such a complex vaccination schedule [24].

One reason cited for low vaccination rates is often missed opportunity [25]. If a child is in to see a physician for a reason other than routine vaccinations, the physician may not take that opportunity to vaccinate the child. MCIR and other IISs play an important role in reducing missed opportunity because they can be used in to produce vaccination reminders when it is time for a child to come in, and recall notices can be produced when a child is late for his/her vaccination [25]. Such reminder and recall notices can also be generated to send directly to homes, so parents are aware that a child is due for a vaccination [25]. Studies looking at offices where reminders and recalls are regularly used have an overall increase in vaccination coverage for children from all different population subgroups [25].

As can be seen in Table 1, region 6 had quite a remarkably lower vaccination rate that region 4 . We believe this may be partially due to region 6 being more rural and being "whiter." 
However, these things were adjusted for in multivariable analyses, and the difference in vaccination receipt still persisted. Lower vaccination receipt in region 6 may also be explained in part by differences in the culture and/or beliefs between providers and residents in different regions. For example, there may be difference in beliefs about the need for or effectiveness of vaccines between regions, but MCIR does not collect any information on this. We also do not have any data on vaccine promotion by region, and this may be a factor influencing differences between regions.

4.1. Strengths and Limitations. A strong point of this study is the high quality of the data from MCIR. At the end of 2007, more than 95\% of children 19-35 months of age had at least two recorded vaccinations in MCIR, and approximately 91\% of the 2255 Michigan childhood vaccination providers submitted data to MCIR from July to December 2007 [16]. With such high participation rates, and a large sample size, we are confident that Michigan's population of one-year-olds was well represented in this data set.

The MCIR has some limitations that tend to bias its vaccination coverage measures downward. Although reporting of childhood vaccinations is legally required [26] in Michigan, some vaccinations go unreported. Newly required vaccinations may also be subject to more incomplete reporting or more data entry error. MCIR is not always notified when children move out of Michigan. Therefore, if an unvaccinated child leaves the state and is subsequently vaccinated, that child could still be considered an unvaccinated Michigan resident in MCIR, further biasing vaccination coverage downward. Actual vaccination coverage levels in Michigan are probably slightly higher than estimates from MCIR.

Bias in vaccination reporting to MCIR is a concern because of inherent differences in the types of people who visit doctors, and in the type of doctors who consistently update MCIR information. Although participation in MCIR is good overall, local health departments tend to participate more fully than private health care providers, and some race/ethnic groups may be more likely to visit public providers. For example, a larger percentage of American Indian, Hispanic, and black one-year-olds received their vaccinations from public providers than white one-year-olds. In addition, southeast Michigan has had lower MCIR participation than the rest of the state; since $83 \%$ of the residents of the city of Detroit (which is in southeastern Michigan) are black [27], we cannot entirely exclude differential reporting of vaccinations based on race, geographic region, type of health care provider, or insurance status. It is difficult to know how these biases might affect our results.

The multivariable analyses in this study were limited to one-year-olds who were born in Michigan because some of the explanatory variables were provided to MCIR via Michigan's electronic birth certificate. If a child was born outside Michigan, MCIR would lack electronic birth certificate information, which would lead to missing values for some of the explanatory variables, causing that record to be excluded from the model.

Although this analysis found significant associations between hepatitis A vaccination and several factors, the final model has low pseudo- $R^{2}$ (Nagelkerke $R^{2}=0.01$ ). This indicates that other variables that were not included in our analysis may be needed in order to fully explain the variation in hepatitis A vaccination coverage. This indicates that further research may be necessary to determine more important factors associated with vaccination. Likely candidates include socioeconomic status and education, which we were not able to measure directly.

4.2. Conclusions and Future Directions. These data provide a baseline for hepatitis A vaccination coverage in Michigan one-year-olds following the recommendation of hepatitis A vaccination for children nationwide. As shown in this study, IISs are a valuable tool, as the data gathered within them can be used to see if there are specific subgroups of a population not getting a vaccination or getting a vaccination at higher rates than the rest of the population [25]. Data extracted from MCIR can also be used by public health officials to direct vaccine-specific education and outreach programs directly towards underserved populations [25]. Studies have shown when vaccination education programs are paired with other strategies like reminder/recall, vaccination coverage increases for all subgroups of a population [25].

Further outreach efforts may be needed to increase hepatitis A vaccination levels among those not receiving the vaccination, and these efforts should be specialized to this vaccine as its trends appear different from other vaccines. Michigan will continue to monitor trends in hepatitis A vaccination coverage. Future studies could examine potential underlying causes for increased and decreased odds of vaccination receipt in specific groups.

\section{Acknowledgments}

A. Weston was funded by the University of Michigan School of Public Health Department of Epidemiology as part of an externship with the Michigan Department of Community Health. The data was presented as a poster at the 2008 Annual Michigan Epidemiology Conference in Lansing Michigan, and as a talk at the July 2007 West Michigan Epi-Exchange Meeting. The authors would like to acknowledge Patricia Vranesich, Lynda Lisabeth and JoLynn Montgomery for their assistance in editing the manuscript. They have no disclosures or conflicts of interest.

\section{References}

[1] B. P. Bell, C. N. Shapiro, M. J. Alter, et al., "The diverse patterns of hepatitis A epidemiology in the United Statesimplications for vaccination strategies," Journal of Infectious Diseases, vol. 178, no. 6, pp. 1579-1584, 1998.

[2] J. J. Amon, N. Darling, A. E. Fiore, B. P. Bell, and L. E. Barker, "Factors associated with hepatitis A vaccination among children 24 to 35 months of age: United States, 2003," Pediatrics, vol. 117, no. 1, pp. 30-33, 2006.

[3] S. R. Bialek, D. A. Thoroughman, D. Hu, et al., "Hepatitis A incidence and hepatitis A vaccination among American Indians and Alaska Natives, 1990-2001," American Journal of Public Health, vol. 94, no. 6, pp. 996-1001, 2004. 
[4] Committee on Infectious Diseases, "Hepatitis A vaccine recommendations," Pediatrics, vol. 120, no. 1, pp. 189-199, 2007.

[5] A. E. Fiore, A. Wasley, and B. P. Bell, "Prevention of hepatitis A through active or passive immunization: recommendations of the Advisory Committee on Immunization Practices (ACIP)," Morbidity and Mortality Weekly Report, vol. 55, no. RR-7, pp. $1-23,2006$.

[6] C. N. Shapiro, P. J. Coleman, G. M. McQuillan, M. J. Alter, and H. S. Margolis, "Epidemiology of hepatitis A: seroepidemiology and risk groups in the USA," Vaccine, vol. 10, supplement 1, pp. S59-S62, 1992.

[7] A. Wasley, A. Fiore, and B. P. Bell, "Hepatitis A in the era of vaccination," Epidemiologic Reviews, vol. 28, no. 1, pp. 101-111, 2006.

[8] A. Werzberger, B. Mensch, D. R. Nalin, and B. J. Kuter, "Effectiveness of hepatitis A vaccine in a former frequently affected community: 9 years' followup after the Monroe field trial of VAQTA ${ }^{\circledR}, "$ Vaccine, vol. 20, no. 13-14, pp. 1699-1701, 2002.

[9] CDC, "Prevention of hepatitis A through active or passive immunization," Morbidity and Mortality Weekly Report, vol. 45, no. RR-15, pp. 1-30, 1996.

[10] CDC, "Prevention of hepatitis A through active or passive immunization: recommendations of the advisory committee on immunization practices (ACIP)," Morbidity and Mortality Weekly Report, vol. 48, no. RR-12, pp. 1-37, 1999.

[11] CDC, "Prevention of hepatitis A through active or passive immunization: recommendations of the advisory committee on immunization practices (ACIP)," Morbidity and Mortality Weekly Report, vol. 55, no. RR-7, pp. 1-23, 2006.

[12] A. Fiore, L. C. Baxter, B. P. Bell, et al., "Hepatitis A 2004 vaccination in children. Methods and findings of a survey in two states," American Journal of Preventive Medicine, vol. 33, no. 4, pp. 346-352, 2007.

[13] E. C. Owen, K. M. Peddecord, W. Wang, et al., "Hepatitis A vaccine uptake in San Diego County: Hispanic children are better immunized," Archives of Pediatrics and Adolescent Medicine, vol. 159, no. 10, pp. 971-976, 2005.

[14] American Immunization Registry Association, "Registry profile-Michigan childhood immunization registry," January 2008, http://www.immregistries.org/public.php/ImmRegs/ regMain.php?MainButton=Details\&id=25.

[15] A. R. Hinman, G. A. Urquhart, and R. A. Strikas, "Immunization information systems: National Vaccine Advisory Committee Progress report, 2007," Journal of Public Health Management and Practice, vol. 13, no. 6, pp. 553-558, 2007.

[16] The National Center for Immunization and Respiratory Diseases, "Section IX. Immunization registr," JanuaryDecember 2007, http://www2a.cdc.gov/nip/irar/grantee/ giregistry2007.asp?projectID=522556.

[17] Rural Health Research Center, "Rural-urban commuting area codes," July 2007, http://depts.washington.edu/uwruca/.

[18] K. G. Wooten, L. T. Luman, and L. E. Barker, "Socioeconomic factors and persistent racial disparities in childhood vaccination," American Journal of Health Behavior, vol. 31, no. 4, pp. 434-445, 2007.

[19] S. Sabnis, A. J. Pomeranz, and J. Mao, "Physician beliefs and practices regarding the use of hepatitis A vaccine," Wisconsin Medical Journal, vol. 106, no. 4, pp. 211-214, 2007.

[20] T. A. Santibanez, J. M. Santoli, C. B. Bridges, and G. L. Euler, "Influenza vaccination coverage of children aged 6 to 23 months: the 2002-2003 and 2003-2004 influenza seasons," Pediatrics, vol. 118, no. 3, pp. 1167-1175, 2006.

[21] CDC, "Influenza vaccination coverage among children aged 6-23 months. United States 2006-2007 Influenza Season,"
Morbidity and Mortality Weekly Report, vol. 57, no. 38, pp. 1039-1043, 2008.

[22] CDC, "National Immunization Survey (NIS)—children only," October 2008, http://www.cdc.gov/vaccines/stats-surv/ imz-coverage.htm\#nis.

[23] American Academy of Pediatrics CoPaAM, "Recommendations for preventive pediatric health care," Pediatrics, vol. 96, no. 2, pp. 373-374, 1995.

[24] K. M. Hillenbrand, "What is going on with vaccines: keeping up with the childhood immunization schedule," Journal of Public Health Management and Practice, vol. 13, no. 6, pp. 544-552, 2007.

[25] Task Force on Community Preventive Services, "Recommendations regarding interventions to improve vaccination coverage in children, adolescents, and adults," American Journal of Preventive Medicine, vol. 18, no. 1, supplement 1, pp. 92-96, 2000.

[26] State Office of Administrative Hearings and Rules, Department of Community Health community public health agency childhood immunization registry, October 2008, http:// www.state.mi.us/orr / emi/ admincode.asp? AdminCode=.asp? AdminCode $=$ Single $\&$ Admin $\_N u m=32500161 \& \mathrm{Dpt}=\mathrm{CH}$ \&RngHigh $=$.

[27] U.S. Census Bureau. Detroit city, Michigan. American Fact Finder 2007, January 2008, http://factfinder.census.gov/home/ saff/main.html? lang=en. 

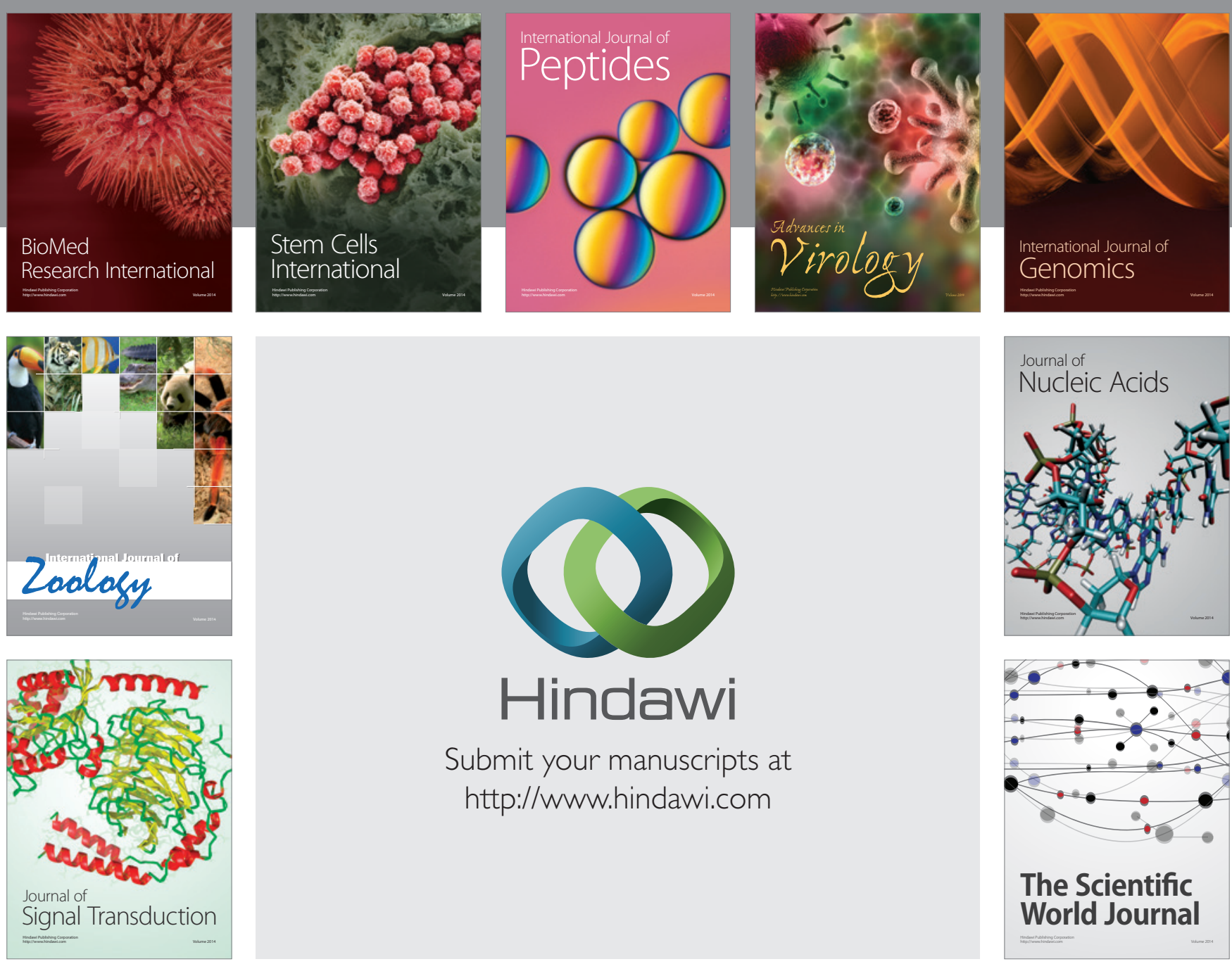

Submit your manuscripts at

http://www.hindawi.com
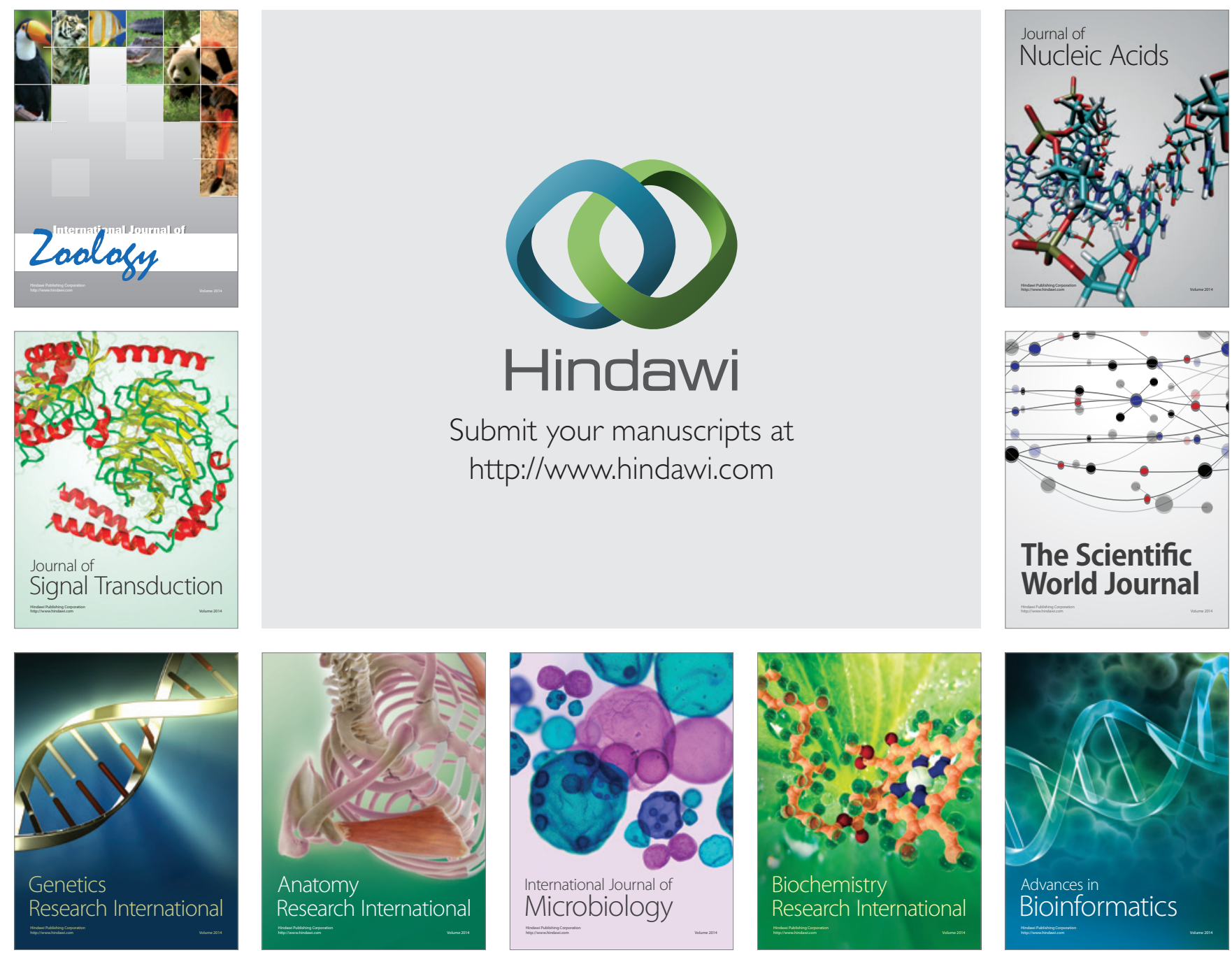

The Scientific World Journal
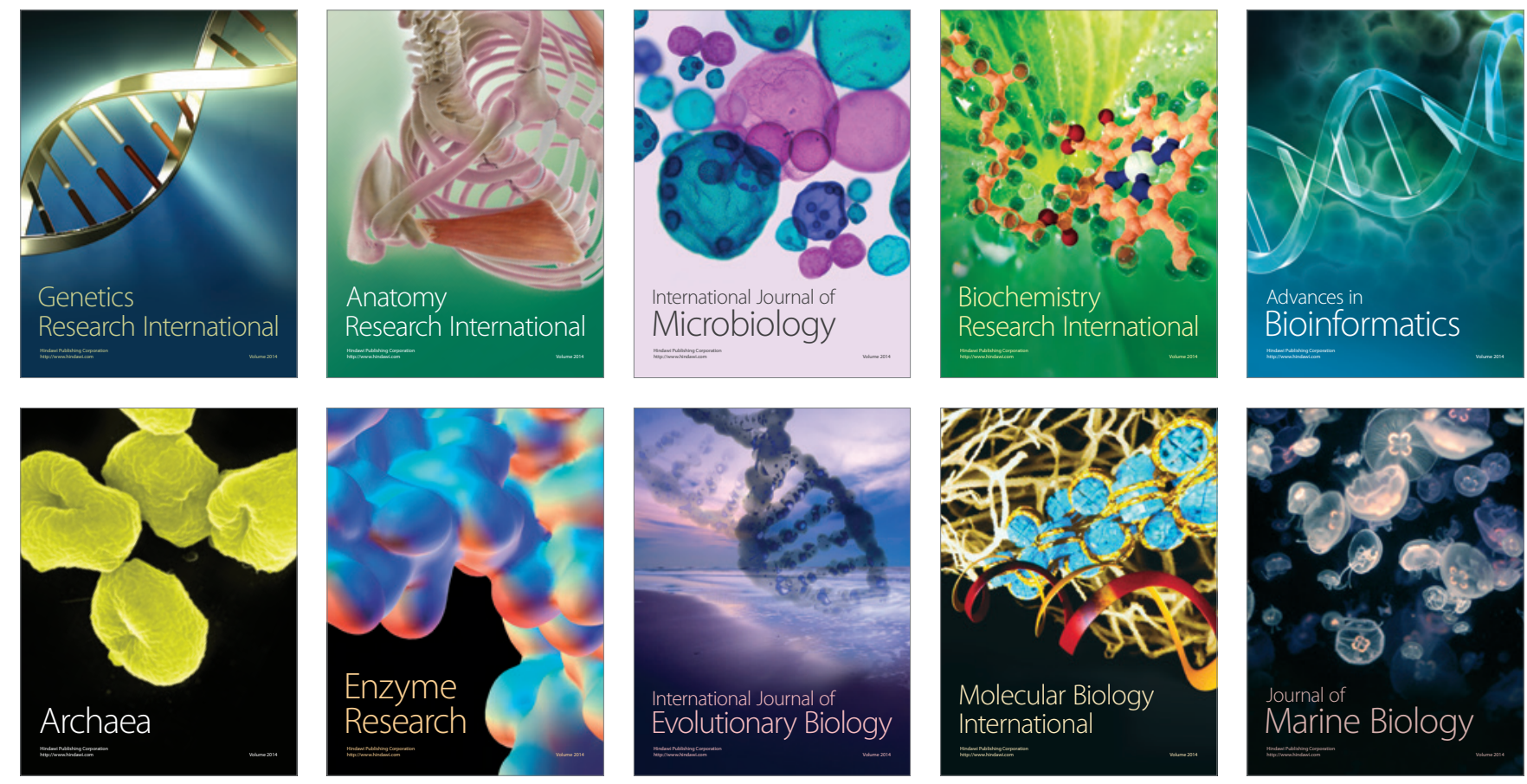